E.L.U.A., 6, 1990, pp: 9-21.

\title{
ESBOZOS DE DOS ESTUDIOS DE LEXICOLOGÍA DIACRÓNICA
}

\author{
YAKOV MALKIEL \\ (Universidad de California en Berkeley)
}

\section{I. (A)rrematar, (a)rrebatar y (a)rremeter}

Según la opinión casi unánime de varios aficionados de la lexicología regional peninsular y de alguno que otro especialista en el terreno tan resbaladizo del comparatismo románico, existe en español dialectal un uso del verbo arrematar (el cual, a su vez, parece remontarse a un ramo de la familia bastante extensa de matar, muy controvertida desde hace siglos en el gremio de los etimologistas profesionales). Es precisamente la necesidad de reanudar la discusión multisecular de matar y de las principales ramas de su linaje la que nos empuja a prestar atención al problema afín de (a)rrematar.

El problema de la descendencia no fue planteado directa y expresamente por Max Leopold Wagner en el último y más maduro de sus tres estudios de conjunto sobre el judeo-español de Oriente'; sin embargo, Wagner reunió varios materiales útiles y de categorías heterogéneas, para los cuales encontró un denominador común. Este elemento -medio semántico, medio sintácticoque comparten sus hallazgos los aleja notablemente de la tradición mejor conocida de rematar y, en última instancia, de la de matar:

«ARREMATAR se usa en jud[eo]-esp[añol] de hoy sobre todo en la forma de imperativo y en el sentido de 'apártate', 'vete al diablo', así en una conseja constantinopolitana, publicada por mí, [Beiträge zum] J[u]d[en]sp[anischen] v[on] K[onstantino]pel, col. 37: La mučača le dišo: arremata de aki, y en un romance

\footnotetext{
'Max L. Wagner, «Espigueo judeo-español», en RFE, 24 (1950), 9-106; véase la pág. 28.
} 
publicado por A. Danon, pág. 266: «Remata, Delgadilla, / Remata, perra mala», traducido: 'au diable, D., au diable, mauvaise chienne!' Claro está que el sentimiento originario es '¡acaba!'. Arrematasjión es en Bulg[aria] 'el acto de huir'»"

Wagner se olvidó de subrayar el hecho de que se trata, en el fondo, de dos verbos distintos, aunque de uso casi igual, rematar y arrematar, circunstancia que, por lo demás, no se opone a su conjetura.

Arrematar, como sinónimo de rematar, también ha dejado huellas en España; la última edición del diccionario de la Academia tacha esa variante de "familiar", pero no la localiza, atribuyendo a (a)rrematar el significado de "dar fin a una cosa' (pág. 130a). Como, hasta cierto punto, coexisten, en español peninsular, o coexistían en un pasado no muy remoto, arrebatar y rebatar, arrellenar y rellenar, arremangar y remangar, arremedar y remedar, arremembrar y remembrar, arrempujar y (r)empujar, a veces con matices semánticos algo distintos, otras veces con muy ligera diferenciación formal (como en el caso de arrepanchigarse frente a repantigarse, que también pertenecen al nivel familiar del léxico), la ocasional convivencia de arrematar y rematar, en el uso peninsular de esta pareja de voces, no ha de causar muchos quebraderos de cabeza.

Me parece que el núcleo de la hipótesis de Wagner, de hecho, es sostenible, con tal que no se insista dogmáticamente en un desarrollo en forma de línea recta. Es concebible el parentesco que postuló, un poco apresuradamente, el romanista bávaro, mientras se admitan influjos laterales y cierto zigzagueo. Sospecho que se produjo una asociación secundaria de (a)rrematar, por lo menos, con dos verbos muy característicos del español medieval $-\mathrm{y}$, por tanto, bien documentados: (a)rremeter y (a)rrebatar. Los dos compartían con (a)rrematar la alternancia muy visible de los elementos re-y arre-. Por añadidura, (a)rrematar y (a)rremeter coincidían por entero en su arquitectura consonántica: $-r r-,-m-$, -t-, pero divergían en su conjugación: -ar frente a -er. Por otro lado, (a)rrematar y (a)rrebatar mostraban, es cierto, un parecido menos marcado en el contorno de su consonantismo, pero, por compensación, una identidad total en su comportamiento morfológico. Por añadidura, en la intrincada red de matices semánticos de los dos verbos aludidos no faltan algunos que armonizan a maravilla con lo que nos llamó la atención hace poco, en la notable estructura

\footnotetext{
${ }^{2}$ El texto de Danon figura en su artículo «Proverbes judéo-espagnols», que salió en la $Z R P h, 37$ (1900), 72-96. En cuanto a la forma recogida en Bulgaria, es probable que se la comunicó a Wagner el Dr. Paul Mézan (o uno de sus amigos), con quienes Wagner, ya domiciliado en Berlín, estableció un contacto en los años veinte y treinta. El trabajo principal de Mézan es: Les Juifs espagnols en Bulgarie, Sofía, 1925. En cuanto a la obra anterior de Wagner a que aludió en su monografía del año 1950, se trata del siguiente trabajo de desbroce: Beiträge zur Kenntnis des Judenspanischen von Konstantinopel, t. 10 (1914) de la colección: Kaiserliche Akademie der Wissenschaften [Wien], Schriften der Balkankommission (Linguistische Abteilung).
} 
del significado de la voz judeo-española, y lo mismo se puede declarar a propósito de ciertas peculiaridades sintácticas cuya presencia queda por explicar; por ej., la construcción reflexiva. En resumidas cuentas, el análisis propuesto por Wagner merece que se ejecute con cierta cautela.

Del antiguo verbo remeter, todavía bastante común en textos de la Edad Media, no se han conservado en la lengua moderna, según el veredicto de la Academia, más que algunos usos marginales; este residuo comprende los matices siguientes: 'volver a meter', 'meter más adentro' y 'ponerles a los niños un metedor limpio, sin quitarles los pañales'. En los demás contextos, en que estaban prácticamente intercambiables remeter y arremeter, triunfó éste a costa de aquél. Además, el verbo compuesto está rodeado de toda clase de derivados de función transparente: según la autoridad ya invocada, el sust. arremetedero equivale a 'paraje por donde puede atacarse un lugar fuerte' (prestando servicio como término militar); arremetedor actúa de adjetivo, equivaliendo a 'que arremete'; arremetida y arremetimiento constituyen dos abstractos rivales: 'acción de arremeter'.

En cuanto a su armazón sintáctico-semántica, se ve a las claras que el verbo, representado con abundancia en lo antiguo, ya ha perdido mucho terreno. La Academia no titubea en tachar de «desusado» el sentido - de gran pertinencia para el historiador ${ }^{3}$ - 'hacer al caballo arrancar con ímpetu', mientras reserva el marbete «anticuado» para la construcción pronominal 'meterse con ímpetu, acometer' igual que para un empleo traslaticio: 'ponerse, arrogarse algún título o dignidad'4. Es de innegable importancia para nuestra pesquisa el siguiente matiz: 'arrojarse con presteza', ya que parece hacer eco al uso de arrematar señalado por Wagner con motivo de su sondeo del judeo-español. La elasticidad del uso, pasado o moderno, prorrumpe también en el ocasional empleo figurado o familiar de la voz: 'chocar, disonar u ofender a la vista alguna cosa'.

La prehistoria de (a)rremeter; su inmediato modelo latino; su relación con remitir; su gradual marcha en retirada ante determinados sinónimos (ante todo, atacar); cierto paralelismo quizás no enteramente fortuito entre las trayectorias

${ }^{3}$ A. Ennout y A. Meillet, Dictionnaire étymologique de la langue latine, 4" ed., Paris, Klincksieck, 1959-60, pág. 407b, atribuyen a Varrón, De lingua Latina, el uso de la expresión mittere equos, que caracterizan como uno de los eslabones entre el significado primitivo de mittere ("Jaisser aller, laisser partir, lâcher, lancer') y el sentido más familiar a estudiosos de los textos clásicos ('envoyer').

${ }^{4}$ Por lo demás, la clasificación de los significados de arremeter que ofrece la Academia, aún en 1984, no merece llamarse un modelo de lógica. No se reconoce con claridad el límite que separa el uso tercero ('arrojarse con presteza'), falto de cualquier calificación, del quinto ('meterse con ímpetu, acometer'), calificado de anticuado y de pronominal. Esta deficiencia es tanto más lamentable cuanta mayor la afinidad de ambos usos en cuestión con el arrematarse de los sefardíes. Resulta más concentrada y, por lo tanto, preferible la triple definición que suministró el Diccionario ideológico de la lengua española (Barcelona, Ed. G. Gili, 1942, pág. 93a) de J. Casares: arremeter tr. 'acometer con ímpetu y furia', intr. 'arrojarse con presteza'; fig. y fam. 'chocar, desconvenir, ofender a la vista alguna cosa'. 
de (a)rremeter y (a)cometer (ambos verbos basados, a fin de cuentas, en las peripecias del verbo latino mittere): todos estos problemas, sin la menor duda, encierran marcada importancia, sin que se pueda prestarles ahora más que un mínimum de atención pasajera ${ }^{5}$.

Una feliz circunstancia facilita todavía más nuestra responsabilidad por una correcta valoración del puesto que desde hace siglos (pero esta vez no milenios) ocupan arrebatar y su familia, de abolengo oriental, en la lexis española. Según estableció J. Oliver Asín en su magistral monografía del año 1928, se trata en este caso excepcional de una familia léxica no latina, sino árabe, siendo el verbo un derivado del sustantivo (re-arre-bato y variantes), y no al revés ${ }^{6}$. El episodio más pintoresco de esta crónica particular es que este grupo de arabismos se dejó arrastrar por la difusión del tipo hispanolatino $a+(r) r+\ldots a r$. Sean los que fueren los pormenores de tal proceso, lo esencial es que, en el pasado, arrebatarse equivalía a 'acudir la gente cuando tocan a rebato'; así, merced a su construcción pronominal (o reflexiva) y al ingrediente de rápido movimiento físico en la gama de sus significados, también pudo allanar el camino al uso judeo-español de arrematarse, como lo definió Wagner a la zaga de Danon y de otros predecesores.

Queda por averiguar si algunos hallazgos de fecha reciente han corroborado, completado o más bien diluido ciertas tesis de Wagner así como los breves comentarios que acaban de agregarse a su resumen. Merece particular atención por su esmero el juicioso diccionario judeo-español de Salónica (redactado en francés) de J. Nehama; quedó revisado, después de la muerte del autor, por J. Cantera ${ }^{7}$. (En el siglo XVI - según ha de constar al lector- Salónica fue el principal centro cultural de los sefardíes desterrados, antes del florecimiento de las comunidades de Livorno y de Amsterdam.)

Ahora bien, Nehama, para comenzar, registra un número elevado de formaciones (principalmente verbales o deverbales) que lucen arre-como elemento inicial: arrebaxar 'rabaisser, humilier' (y arrebaxarse 'prier, demander, s'abaisser pour

\footnotetext{
s Sobre arremeter, como de costumbre, sigue siendo una excelente fuente de información R. J. Cuervo, Diccionario de construcción y régimen de la lengua castellana, t. 1 (Paris, 1886; Bogotá, 1954), págs. 638-641, según confirma J. Corominas, Diccionario crítico etimológico de la lengua castellana, t. 3, Madrid y Berna, 1956, pág. 361. Lo que tienen en común con acometer y arremeter no es solo cierto parecido de mensaje y de estructuración silábica, sino también el hecho de haberse alejado completamente, con el pasar del tiempo, de sus «primitivos» cometer y remeter, cuya conexión histórica con meter, a juzgar por su alejamiento semántico, apenas si se sentía o ya no se sentía del todo. Es muy notable la enorme distancia que separa (a)cometer y (a)rremeter de sus equivalentes formales en francés, commetre y remettre. La relación de -meter (patrimonial) con -mitir (erudito) --sólo existen entremeter y omitir, permitir, transmitir, pero se ha conservado remeter al lado de remitir, con diferenciación semántica muy neta- - trae a la memoria, hasta cierto punto, la rivalidad de -correr y -currir, que examiné pormenorizadamente en mi artículo "The overlap of currere, -cutere, and cor-rigere in Hispano-Romance», $R P h, 38: 2$ (1984), 127-70.

6 «Origen árabe de rebato; arrobda y sus homónimos; contribución al estudio de la historia medieval de la táctica militar y de su léxico», Madrid, 1928 (sobretiro del BRAE).

${ }^{7}$ Dictionnaire du judéo-espagnol, Madrid, Instituto Benito Arias Montano, 1977.
} 
demander une faveur'), arrebivir 'raviver, ramener à la vie', arreboltear 'bouleverser, chambarder', arrebolver 'rappeler, faire allusion', arre $\delta$ ondear 'arrondir', arrefinar 'raffiner', arrefolgar 'se détendre, se reposer', arrefregar 'frotter', arrefrescar 'rafraîchir', etc. Dentro de este marco tan característico sitúan los compiladores el verbo arrematar 'détruire, exterminer, anéantir, donner le coup de grâce', empleado en toda clase de maledicciones enérgicas y aun pintorescas: déxalo arrematar 'envoie-le au diable', ya se arremató 'on l'a déjà liquidé', arrematar a uno con syete pares de diavlos 'envoyer quelqu'un à tous les diables', ;arrémata! 'va-t-en au diable!'; es admisible la construcción reflexiva, la cual parece agregar poco al mensaje: arrematarse 'déguerpir, quitter précipitamment un lieu où l'on a éprouvé une forte déception, partir, s'éloigner, en parlant d'un individu tout à fait indésirable' (pág. 52a). En la galería de cuadros de la vida doméstica que dibujó, a pinceladas vigorosas, Nehama, recordando a buen seguro ciertas escenas de su propia vida antes de 1941, aparece además el adjetivo participial arremata $\delta o$ 'exterminé par ordre de la Providence', (jarrematado lo vea! 'puisse Dieu l'exterminer!'); y los dos sustantivos abstractos, resultando el derivado por medio de -myento mucho menos común que su rival en -syón:..ma no kyero pelear arrematasyón! Dale lo que demanda i que se kede kayado. Aquí me alejo algo de la redacción del diccionario, opinando que arremetasyón ha terminado por convertirse en una interjección, lo que resulta también del comentario siguiente: «Se profère avec dépit, avec résignation et amertume...».

Otros aspectos de pesquisas post-wagnerianas pueden causar cierto desengaño. $\mathrm{Si}$ aun sobrevivía en Salónica, en pleno siglo XX, rematar como mera variante de arrematar (es decir, como equivalente, para hablar con Nehama, de 'donner le coup de grâce, exterminer'), los dos núcleos arremeter y remeter ya asumían otras responsabilidades, que despiertan la sospecha de un fuerte influjo francés ( ¿ejercido a través de la red de escuelas de la Alliance Française?). No se reconoce el más mínimo grado de continuidad, de transmisión directa (oral) entre el (a)rremeter de la Edad Media española y las siguientes palabras recogidas por Nehama hacia mediados de este siglo: remesa 'remise, envoi'; remeter 'ajourner, renvoyer'; remeterse 'revenir à la santé, se mettre à nouveau'; remeti $\delta o$ 'revenu à la santé, rétabli'; remeti iko 'dont la santé, l'état de fortune s'est légèrement amélioré' (pág. $473 \mathrm{ab);} \mathrm{y} \mathrm{arremeterse} \mathrm{'se} \mathrm{remettre,} \mathrm{regagner} \mathrm{sa} \mathrm{santé';} \mathrm{arremeti \delta o}$ 'remis, revenu à un bon état de santé, de fortune'; arremetidiko 'un peu plus remis, mieux portant, mieux consolidé'. A la inversa, en seguida se reconoce el ámbito semántico de remise, se remettre, etc., pero indudablemente en disfraz hispánico, por ej., con arre- a trueque de re-. Parecida presión del francés era inoperante antes del siglo XIX; así, nuestra hipótesis del influjo que pudo haber ejercido (a)rremeter en (a)rrematar no queda eliminada, pues de hecho pudo actuar en los siglos XVI-XVIII. Pero ya no es tan fácil como antes conjeturar que un verbo que se dejó aplastar por la invasión de un congénere francés en el 
siglo XIX haya tenido la fuerza, allá por 1550 , de ejercer un influjo decisivo en ciertas peripecias de arrematar ${ }^{8}$.

En cuanto al arabismo ya señalado (a)rrebatar, sí estaba representado en el habla de Salónica, de preferencia por su variante alargada. Así el diccionario a que hemos acudido registra: 's'emparer avec brutalité, piller, arracher' (=ečarse a arrevatar), 'dévorer'; arrevatarse 'cuire trop vite et mal (un plat), brûler avant de cuire', 'dévorer, manger gloutonnement'; arrevatado 'ravi avec brutalité, capturé par les brigands, dévoré par les fauves', 'avalé, absorbé avec précipitation', 'cuit trop vite sur un feu trop vif'; arrevatamyento 'rapt, action de ravir'. Por lo visto, no hay modo de poner en duda la extraordinaria vitalidad de esta familia léxica en judeo-español, máxime en vista de su inesperado diapasón de matices culinarios.

Como se han encontrado huellas aisladas o espotádicas de (a)rrematar(se) en varias zonas o distintos rincones del dominio judeo-español, surge el inevitable problema de si se trata, de hecho, de una innovación (quizás relativamente antigua) de los sefardíes o de si se hallan por lo menos unos vestigios sueltos de tal neologismo en los dialectos de la península. Wagner, en los años cuarenta, no topó con ninguna huella de semejante uso de arrematar en las hablas rústicas de la Península que logró observar por el prisma de los vocabularios regionales. ¿Qué cambio, en este respecto, se ha producido en el transcurso del último medio siglo?

A título de contestación provisional pongo de relieve la frecuencia del segmento arre- en navarro (arrecogido 'recogido, acogido'; arretaguardia 'retaguardia'); y llamo la atención al lector sobre el uso, en aquella provincia (y particularmente en la Ribera), de arrematarse de + infin. 'acabar de' (jarremátate ya de peinarte!), ante todo en exclamaciones acompañadas de gritos, lo cual coincide con las preferencias, ya señaladas, del judeo-español. Además siguen usándose en aquella zona (pero se dejan comprobar también con textos del siglo XVIII) rematado, pronunciado rematáu, 'completo, absoluto' (cf. el giro adverbial castellano de remate así como remate 'subasta' y la expresiva fórmula en último remate 'en fin de cuentas'); un loco rematáu; la gama semántica del mismo adjetivo: 'muy malo, horrible, malvado, avieso'; 'cansado, fatigado'; y la construcción verbal rematarse de (o estar rematado de) + infin. 'fatigarse mucho, cansarse, agotarse'. Por estas alturas, ya no andamos muy alejados del uso sintáctico, semántico y estilístico (en lo relativo a la entonación) del judeoespañol ${ }^{9}$.

${ }^{8}$ Es extraordinario el número de galicismos que ha recogido el diccionario de Nehama (exento de cualquier tentativa de purismo).

"Véase J. M. Iribarren, Vocabulario navarro, Pamplona, Institución «Príncipe de Viana», 1952, págs. 60a y 440a; Idem, Adiciones al vocabulario navarro, Pamploná, Institución «Príncipe de Viana», 1958, pág. 24. Las autoridades en que se apoyaba el autor eran: J. A. Larrea (1782): «E】 mesón es cosa rematada», y A. Ponz. No deja de ser curioso que ya el viejo lexicógrafo J. Borao, Diccionario de voces aragonesas, $2^{\text {a }}$ ed., Zaragoza, 1908, pág. 167, se refirió a arrematar 'dar término o fin', apoyándose en un elocuente pasaje de la Crónica rimada del Cid. 
Sumando y filtrando todo lo observado hasta ahora, podemos suavizar así los juicios medio apodícticos de Max L. Wagner. El verbo (a)rrematar muestra una evolución excepcionalmente animada en judeo-español, eso sí, pero también en español antiguo y en el nivel dialectal del español contemporáneo (por ej., en Navarra), lo cual produce la impresión de conjunto de que, tipológicamente, su uso en Salónica, Constantinopla, etc., no se alejó radicalmente de la norma peninsular. Queda por descubrir la cuna exacta de ciertas idiosincrasias; es verosímil que algunas ya nacieron en las juderías del destierro. No se puede descartar la sospecha de que algunas innovaciones, de las más atrevidas, se deben a contactos espontáneos con otros verbos de apariencia parecida; dentro de este grupo, la biografía del arabismo arrebatar se presta mejor a la reconstrucción que la de arremeter, amenazado por la constante presión del fr. remettre, más en lo semántico que en lo formal. Por lo demás, alguno que otro miembro de la familia tendía a convertirse en interjección, lo cual de rechazo pudo acelerar su desarrollo semántico y sintáctico (;arrematación!). Cualquiera que fuese la verdadera concatenación de los sucesos, es altamente improbable que exija del investigador que revise radicalmente su opinión sobre el origen de matar.

\section{Español menudencia, portugués miudeza}

A primera vista, no despierta ninguna grave inquietud descubrir el esquema de derivación del abstracto adjetival menudencia, ya que el deslinde de sus principales elementos, el radical y el sufijo ${ }^{10}$, no podía ser más claro. Además, la etimología de menudo (a saber, el lat. minūtu, acompañado del adverbio minūtim) es enteramente transparente y la estructura de la familia léxica en cuestión (el adverbio minus, el verbo minuere, etc.) no causa dificultad alguna en el nivel cronológico del latín. Sin embargo, nada por el estilo pasa con el fr. menu, mientras el equivalente portugués miudo, en estrecho enlace con su abstracto miudeza, sí causa sorpresa ${ }^{11}$, siendo decididamente excepcional que el sufijo

\footnotetext{
${ }^{10}$ Lo común, desde luego, es que el esp. -encia corresponde ora a -ença (patrimonial), ora a -ência (culto, latinizante) en gallego-portugués, por ej. dolencia/doença, ciencia/ciência, mientras que el sufijo -eza está a caballo de los dos idiomas (nobleza/nobreza), si bien en casos individuales siempre es posible que sea en español, sea en portugués aparezca -ez en lugar de -eza. Tampoco faltan ejemplos del predominio de la variante -icia en uno de los dos idiomas en cuestión, así el español opone avaricia (afín al ingl. avarice) al port. avareza. Por añadidura, el propio español todavía cuenta (o hace poco tiempo contaba) con unos cuantos casos de titubeo, empleándose altivez al lado de altiveza, sin la menor diferenciación semántica. Sobre esta materia intrincada así como sobre algunas huellas de la forma - eça en aragonés antiguo (variante que se acerca más que las otras al prototipo latino - ltia) han salido recientemente varios artículos, que no me detengo en enumerar; véase mi sinopsis preliminar en el Bulletin of Hispanic Studies, 65 (1988), 1-19.

"Y está bien lejos de ser la única peculiaridad sorprendente, puesto que a la trivialísima frase adverbial a menudo 'con frecuencia' del español antiguo y moderno le corresponde en portugués, hasta la edad presente, el curioso adverbio amiúde, compuesto de $a<a d$ y miúde <minütim (según
} 
-eza en la faja occidental de la península corresponda a -encia en su región central.

Mirando las cosas más de fijo, en seguida se echa de ver que menudencia, en realidad, representa una formación bastante anómala. Sus dos rasgos más extraños, que no tardarían en chocar a cualquier sólido latinista, son, para comenzar, el hecho de que un instrumento de derivación de carácter tan erudito como-encia se haya unido aquí, a título de excepción, a un radical enteramente patrimonial, como lo es, sin sombra de duda, menud-. Además, -encia heredó de su inmediato prototipo clásico la capacidad de adherirse al radical del infinitivo (del presente) igual que de los tiempos simples del verbo más bien que al del participio pasado: cf. ciencia, diferencia, experiencia, magnificencia, ponencia, providencia, prudencia, reticencia, sugerencia, tenencia, etc. Dadas tales y tantas extrañezas, se impone la necesidad de examinar con mayor detenimiento las vicisitudes del sufijo -encia, nada fácil de manejar para el hablante y aun el escritor de fines del siglo $\mathrm{XV}^{12}$.

Empiezo por resumir cuanto ya se ha establecido en pesquisas anteriores. En la capa más antigua del léxico español coexistían los sufijos -ança y -iença, preferidos ambos en voces patrimoniales, así como -ancia y -encia (a veces -iencia ${ }^{13}$ ), característicos de cultismos.

Con notable rapidez, todavía en plena Edad Media, se extinguió del todo-iença, excepto en la voz simiença, mod. simienza, aislada por haber dejado -iença de funcionar en ella como sufijo. De ordinario se sobrepuso -encia a -ença, sin que -ancia siguiese su ejemplo en lo relativo a -ança, de modo que terminó por quedar destruida la inicial simetría del desarrollo.

La desaparición casi instantánea, ante todo en las dos Castillas, de -iença trajo consigo varias confusiones e irregularidades ${ }^{14}$. Así, ${ }^{*}$ pre-, ${ }^{*}$ pri-miença, que en realidad se relacionaba, en un principio, con la prole del verbo premere 'apretar', se convirtió paulatinamente en un brote de prim(o) 'primero' por asociación con primicias, etc. Pendencia, producto de poenitentia (literalmente: 'arrepentimiento en voz alta, dolorida, apasionada'; cf. port. ant. peendença),

razonó con acierto V. García de Diego, criticando a este propósito el análisis de J. Corominas), siendo escasísimos los ejemplos de la perduración, en una lengua románica, del sufijo adverbial -im, ya de poca frecuencia en latín clásico.

${ }^{12}$ Me apoyo aquí en mi propio trabajo de principiante, Development of the Latin suffixes -ANTIA and -ENTIA in the Romance languages... (1945), el cual salió en el t. 1 (1943-48) de la serie University of California Publications in Linguistics.

${ }^{13}$ El port. ant. sabença, frente a su modelo sapientia, muestra que predominaba la tendencia de reducir -ientia a -entia. Para no complicar el asunto más de lo necesario, no me detengo en trazar una divisoria entre -entia, compañero de un adjetivo participial en $-\bar{e} n s$, -entis (por ej., potentia), y -entia, compañero de un adjetivo en -entu, -enta (por ej., violentia).

${ }^{14} \mathrm{De}$ algunos de ellos me ocupé en un artículo cuya publicación prácticamente coincidió con la de la monografía precitada: «Three Spanish-Portuguese etymologies: pendencia, primencia, fimencia», Romanic Review, 35 (1944), 307-323. Esta tercera voz, de la cual existe otra variante, menos opaca: femencia, parece representar un expresivo cruce de fide y ve(he)mentia, el cual sugería un apasionado arrebato místico de fe religiosa. Reanudé la discusión de esta voz, poniendo el acento en otras peculiaridades de su evolución, en un trabajo de cosecha más tardía: «La $F$ inicial adventicia en español antiguo (femencia, finchar, fenchir, fallar, finojo)», Revue de Linguistique romane, 18 (1954), 161-191. 
quedó metamorfoseado en una expresión por 'querella ruidosa', atraído por ciertos sugestivos usos jurídicos de pender, etc. El portugués, cuyos hablantes no llegaron a confundir los sufijos -ença y -encia, sigue ignorando parecidas transgresiones de la norma.

En tales circunstancias de titubeo e inseguridad no parece absurdo sospechar que pasó a producirse cierta confusión también en el caso de menudo frente a sus derivados; que menudencia de seguro ( $y$ tal vez, en grado menor, también el port. miudeza) representan unas torpes tentativas paralelas de innovación más bien que unas reliquias de un pasado lejano.

Sobre el caprichoso desarrollo de menudencia (y sus variantes) existe un pequeño corpus de opiniones; me ciño a aducir algunas de las más recientes. Así, Max L. Wagner, en su última síntesis (ya citada) de exploraciones emprendidas en el terreno del judeo-español balcánico, resumió del modo siguiente sus hallazgos a partir del año $1907^{15}$ :

minudensias (Const[antinopla], Bulg[aria]) significa (1) 'cosas pequeñas', (2) 'menudillos de las aves'. El último significado está registrado como término de Colombia por [R. J.] Cuervo, Apuntaciones críticas], \$ 477; de Venezuela, por [B.] Rivodó, pág. 279; y de México, por [F.] Ramos y Duarte, pág. 354, mientras en España menudencia designa hoy 'los despojos menudos del cerdo'.

No deja de ser curioso que el filólogo alemán se haya detenido en señalar unas cuantas formas dialectales balcánicas e hispanoamericanas sin tomarse la molestia de explicar ni el uso peninsular de la Edad Media tardía (sobre el cual otro investigador ya había proyectado luz con anterioridad de un lustro), ni las actuales preferencias regionales de la península ${ }^{16}$.

Con la exagerada prisa que tenía Juan Corominas, hacia mediados del siglo, de llevar a cabo su empresa lexicográfica, no es de extrañar que solía reservar ya en la primera redacción de su diccionario mayor espacio para el presunto centro de cada familia que para los respectivos compuestos o derivados. Aun así, no deja de extrañar que para la discusión de los problemas que plantea la trayectoria de menudencia se haya contentado con... un renglón y medio de la columna izquierda de la página en cuestión ${ }^{17}$. El filólogo de Chicago y Barcelona no prestó la más mínima atención a cuanto se había aclarado en los años 1944, 1945 y 1950; pero por lo menos agregó un dato útil que echábamos de menos en la exposición de Wagner: menudencia en el sentido de 'menudillos' se encuentra en el habla dialectal de Aragón y Murcia. La primera autoridad que aduce es

${ }^{15}$ El autor no se refirió, en 1950, a ninguna de mis indagaciones de los años 1944 y 1945.

${ }^{16}$ iQué lástima que no haya comentado Wagner el contraste entre los dos significados que logró documentar: 'menudillos de las aves' (Constantinopla, Bulgaria) y 'despojos menudos del cerdo' (España)! La diferenciación se remonta a la abstención que practican los judíos devotos (la cual es de inspiración bíblica) de cualquier contacto con la carne del cerdo.

${ }^{7}$ Diccionario crítico etimológico de la lengua castellana, t. 3, Madrid, Gredos, y Berna, Francke, pág. 341 a, s. v. menguar. 
Nebrija, mientras al inmediato predecesor de éste, A. de Palencia, le satisfacía aun el uso de «los menudillos de las gallinas ${ }^{18}$.

Fijémonos en la génesis de menudencia y en el clima que rodeaba su infancia. En la Edad Media era una voz rara vez empleada, a diferencia de formaciones tan comunes como atenencia, atrev(i)dencia, aud-o obd-iencia, avenencia (también aveniencia y avinencia), bienquerencia, captenencia, etc. Ha dejado huellas en el ms. P, relativamente tardío, del Alexandre (2511b); en el Arte Cisoria de Enrique de Villena; en el diccionario «de Romance en Latín» de Antonio de Nebrija; y en las obras de F. López de Villalobos ${ }^{19}$. Dicho de otro modo, pertenece fundamentalmente a la importante segunda capa de formaciones introducida por un conducto u otro, hacia 1400-1450, habiendo compartido así las fortunas de aderencia, adolecencia, afluencia, apar(i)encia, etc. más bien que aquellas de clemencia, coñoc(i)ença, con(s)ciencia, etc., presentes desde los albores de la tradición escrita. Los judíos españoles eran bastante activos en fomentar la extensión de este sufijo; si en los textos del siglo XIII ya pululan ejemplos de pene-, peni-tencia, también de pene-, peni-dencia, no es inverosímil que fue Santob, o uno de los copistas de su obra, quien allanó el camino a la variante (condenada al fracaso) arrepetencia 'arrepentimiento'. No podían menos de producirse varias confusiones a raíz de la mezcla continua de cultismos, semicultismos y voces patrimoniales. Gonzalo de Berceo se atrevió a acuñar agudencia (Milagros, 225d), por las exigencias de la rima o porque le aburría tener que acudir constantemente a agudeza, con lo cual vamos al encuentro de otro caso de la rivalidad - eza -encia, de tanta relevancia para el estudioso de lą biografía de menudencia / miudeza. Carencia 'falta, necesidad' es un cultismo inconfundible, ya usado en el Libro de consolaciones y en un tratado de Villena (ambos de las postrimerías de la Edad Media), y en latín había seguido el rumbo semántico del verbo carêre; pero nadie impedía a un grupo de hispanohablantes medio toscos asociarlo directamente con el adj. caro, que ya se había distanciado de la primitiva órbita de carēre, aun presente en carecer.

Veamos ahora qué cuadro de conjunto de menudencia pinta, en su última redacción (ed. de 1984), el diccionario de la Academia. (Simplifica la exposición de la materia, desentendiéndose de la proyección histórica; tampoco desperdicia la energía del lector con alusiones a usos meramente locales.) Según el juicio de. los académicos, conviene trazar una divisoria entre el sing. menudencia (el cual puede equivaler a 'pequeñez de una cosa', o a 'exactitud, esmero y escrupulosidad con que se considera y reconoce una cosa, sin perdonar lo más menudo y leve', de no haber adoptado la voz sobre el tapete un matiz más

${ }^{18}$ El largo suplemento que encaja en el t. 4 (1958) carece de cualquier agregado a las peripecias de menudencia; las adiciones amplían la documentación de menucias y contienen, por desgracia, una polémica estéril con V. García de Diego en lo tocante al origen del port. amiúde. Tampoco marca un progreso el t. 4, Madrid, Gredos, ca. 1984, del Diccionario crítico etimológico español e hispánico de J. Corominas y J. A. Pascual (véase la pág. 38b).

1) Para identificar los pasajes en cuestión, conviene recurrir a las págs. 115-132 de mi arriba citada monografía del año 1945. 
concreto: 'cosa de poco aprecio y estimación y de que no se debe hacer caso'; y el pl.menudencias, el que puede sugerir al oyente 'despojos y partes pequeñas que quedan de las canales del tocino después de destrozadas', o 'morcillas, longanizas y otros despojos semejantes que se sacan del cerdo', a no ser que se equipare al 'menudillo de las aves' (pág. 899b). El orden de los significados aspira a ser lógico-gramatical más bien que histórico.

Para variar el control que aplicamos a nuestra reconstrucción y para llenar el vacío que dejó alguno que otro predecesor, pasemos a sacar en limpio el testimonio de los dialectólogos de orientación peninsular. Quizás el hallazgo más feliz, por lo preciso de la localización y el realismo de la grafía, sea minuencia con que un fidedigno explorador dio, hace unos cuantos decenios, en un subdialecto del asturiano ${ }^{20}$. También para el español de ultramar contamos con una documentación cada vez más copiosa ${ }^{21}$.

Lo que más llama la atención en tal pesquisa, concebida en clave dialectológica, no es el grado de autonomía que ha terminado por alcanzar menudencia, sino, al contrario, lo bien que encaja, en lo formal igual que en lo semántico, en la total configuración de la familia del adj. menudo, la cual abarca voces como el sust. menudo, el femenino correspondiente menuda (y, en plural, menudas), el diminutivo menudillo así como el importante verbo menudear ${ }^{22}$, todos ellos con sus indispensables variantes locales.

${ }^{20}$ J. Neira Martínez, El habla de Lena, Oviedo, Instituto de Estudios Asturianos, 1955, pág. 259b. Haría falta una definición menos ambigua.

${ }^{21}$ Cito al azar a C. E. Quirarte: «El español usado en Nochistlán» (2), Investigaciones lingüísticas, 1 (1933), 179.

${ }^{22}$ Para el uso del plur. menudos en la literatura de los Siglos de Oro ('partes peores, desperdicios de lares' en el Lazarillo; 'calderilla' en Cervantes, Alemán y Espinel; el giro en menudos 'en fracciones' en Quevedo; todo ello distinto de la frase volver por los menudos 'defender a los pobres' tolerada por Alemán), puede servir de guía $\mathrm{C}$. Fontecha, Glosario de voces comentadas en ediciones de textos clásicos, Madrid, CSIC, 1942, pág. 237. Atestiguan el uso de menudo(s) 'tripas de una res o ave' J. M. Iribarren, Vocabulario navarro, Pamplona, «Príncipe de Viana», 1952, pág. 332; el de menudo 'vientre de cabra o de oveja relleno de pan, arroz, cebolla y especias para morcillas' $G$. A. García-Lomas, El lenguaje popular de las montañas de Santander, Santander, Centro de Estudios Montañeses, 1949, pág. 203; y el de menudo (=callo) 'guiso del intestino y extremidades de la vaca' A. Alcalá Venceslada, Vocabulario andaluz, Madrid, 1951, pág. 399a. Sobre el fem. menuda, empleado casi siempre en el plural, existe una literatura aparte; como portavoz de la tradición asturiana actúa A. Llorente Maldonado de Guevara, Estudio sobre el habla de la Ribera, Salamanca, CSIC, 1947, pág. 240, atestiguando menudas 'leña menuda, astillas y palitos que recogen los niños', mientras otros eruditos señalan las variantes conservadoras del Alto Aragón, con la dental sorda del latín milagrosamente conservada: me-, mi-nutas 'miettes' (Bielsa), 'copeaux de rabot' es lo que cosechó en sus entrevistas W. -D. Elcock, De quelques affinités phonétiques entre l' aragonais et le béarnais, Paris, E. Droz, 1938, pág. 43, coincidiendo por entero con A. Badía Margarit, El habla del valle de Bielsa (Pirineo aragonés), Barcelona, Instituto de Estudios Pirenaicos, 1950, pág. 303a: menutas 'migajas del pan'. Algunas de estas fuentes también consignan menudillo, atribuyéndole significados especiales: en Navarra, 'pan pequeño, salvado (fino)' (Iribarren); en el Pirineo aragonés, 'residuos de la harina' (Badía Margarit). Para el uso folklórico de menudear resulta instructivo consultar el material reunido por A. Malaret, Los americanismos en la copla popular y en el lenguaje culto, New York, 1947, págs. 119, 229. Provee otros hilos de Ariana M. RomeraNavarro, Registro de lexicografía hispánica (=RFE, Anejo 54), Madrid, 1951, pág. 667. 
Tan notable cohesión de la molécula entera de menud- / miud- nos anima a plantear el problema más intrincado de si tiene mérito la subagrupación, bajo la misma etiqueta molecular, de los descendientes, en línea recta, del viejo abstracto latino minūt-ia (derivado como concord-ia, inert-ia, inf ām-ia, infantia, modest-ia, molest-ia, sollert-ia, superb-ia). Podemos permitirnos hacer caso omiso de la transmisión de minútia a título de cultismo, es decir, de minucia, cuya asociación con menudo ha llegado a ser bastante vaga, y de alguno que otro brote, como minucioso y minuciosidad -las tres voces, por lo demás, legadas a varios idiomas, no solo de estirpe románica (por ej., fr. minutieux al lado del al. minuziös). No, se trata más bien del elemento menuz- que cualquier hispanohablante logra reconocer, mediante cierto esfuerzo, en el verbo desmenuzar, muy común, y que corresponde en portugués a esmiuçar, rodeado de variantes nada difíciles de explicar: esmiudar y esmiunçar, al lado de desmiuçar y desmiudar. La principal diferencia entre los dos idiomas emparentados radica en que, en la faja occidental de la península, se ha conservado bastante bien el femenino subyacente: miuça al lado de miuçalha (rara vez miuçalho) ${ }^{23}$, mientras en el centro ha dejado algunas escasas huellas el masculino correspondiente: menuzos 'fragmentos'.

En el nivel del habla dialectal (rústica y regional por definición) se reconoce mucho mejor el contorno del grupo menuz- a través de alguno que otro derivado. Sobresale menucial (a veces menuncial), el cual, en navarro, puede adoptar, según las circunstancias, los significados 'mezcla de cereales', 'las legumbres (en general) y los cereales, excepto el trigo y la avena', según testimonió J. M. Iribarren a mediados del siglo corriente. Menuceles, que registra Corominas, parece característico del aragonés.

Los medievistas, por su parte, se fijaron en la voz anticuada menuza. A F. Hanssen, excelente conocedor del latín, no se le escapó la afinidad tipológica de $d \bar{u} r$-itia $>$ dureza, pigr-itia $>$ pereza con min- $\bar{u} t i a>$ menuza $^{24}$, sin que se atreviese a formular la sospecha de que la propia caducidad de menuza, de rechazo, pudo crear la necesidad o despertar el deseo de acuñar un neologismo tan atrevido (según ya nos consta) como menudencia.

Pasado apenas un año después de la publicación del manual de Hanssen, salió a luz una magistral noticia, sellada por la autoridad de Américo Castro, de un texto desconocido hasta entonces, «Disputa entre un cristiano y un judío», de la primera mitad del siglo XIII; un pasaje elocuente que aun hoy se graba en la memoria de cualquier lector sensible, reza así:

«Di, judío, ¿quántas comendanças son de tu ley?

-Diez.

${ }_{23}$ Véase C. de Figueiredo, Novo dicionário da língua portuguesa, $4^{a}$ ed., Lisboa, A. Bradão, 1925 , t. 1, pág. $635 \mathrm{a} ;$ y t. 2, pág. 187b. Tampoco falta, desde luego, la variante mitunça.

${ }^{24}$ Gramática histórica de la lengua castellana, Halle, Niemeyer, 1913, \$301. 
—Destas diez ¿quántas menuzas se fizieron?

- Seis cientas e treze» ${ }^{25}$.

Agréguese a ese hallazgo tan feliz por su patos, su claridad y su grato arcaísmo el uso del correspondiente verbo menuzar (predecesor de desmenuzar) en representantes tan autorizados de las letras medievales como Gonzalo de Berceo, Santob de Carrión y G. de Segovia, y, en seguida, de tal conjunto de datos se sacará la conclusión, difícil de sacudir, de que, a lo largo de los siglos XIII y XIV, se habían formado dos bloques o alianzas de palabras de parentesco transparente no sólo para filólogos: un grupo en torno a menud- y el otro en torno a menuz-.

Ahora bien: cualquiera que fuese la situación que se cristalizara paulatinamente en cada dialecto, la lengua literaria de las dos Castillas terminó por negarse a aceptar la alternancia de $d$ y $z$ dentro de la misma familia lexical o del mismo paradigma. Pueden alternar, dentro del paradigma de un verbo común, la $g$ y la $/ \Theta / 0 / \mathrm{s} /:$ digo, dices...; hago, haces...; también pueden hacerlo (con menor frecuencia que antes) el diptongo y el monoptongo dentro de una familia: cuerda cordel, pierna pernil. Pero ya hace largo tiempo cesó de ser lícita la convivencia de la $d$ y la $z$, como en menud- y menuz ${ }^{26}$.

Fue ese repentino cambio de norma de compatibilidad (o sencillamente de gusto estético) que, produciéndose bastante tarde (allá por 1400), forzó a los hablantes y escritores a acuñar, a toda costa y a toda prisa, un nuevo abstracto para hacer juego con menud-o en español (y con meúdo, miúdo en portugués). Como, por razones enteramente independientes, -encia, en español, y -eza, en portugués, estaban muy en boga a principios del siglo $\mathrm{XV}$, los hablantes dotados de cierta iniciativa sacaron provecho de ese clima tan benigno $y$, asiéndose de lo disponible, acuñaron menud-encia y miud-eza. Pero no resultaron ser cirujanos suficientemente hábiles como para esconder las cicatrices de la doble intervención quirúrgica.

25 Véase el t. 1 (1914): 173-180 de la Revista de filología española.

26 Se reconoce cierto paralelismo entre a) la aversión de los hablantes hacia el enlace de los grupos menudo y menuza / menuzar, cada uno rodeado de su sistema de satélites, y b) su hostilidad hacia la conservación del puente que, en un principio, unía fe(e) < fide a fiuza (y sus variantes) 'confianza' < $f \bar{u} d \bar{u} c i a$; del antiguo verbo afiuzar (o, con metátesis, afuziar) 'tener confianza en' no se ha mantenido más que una pareja de lejanos congéneres, a saber, desahuciar y desahucio. Según muestran desmenuzar y desahuciar, el prefijo des- parece haber protegido ciertos miembros de familias condenadas al derrumbe. Véase mi artículo, que todavía no refleja este nuevo modo de pensar: «La fragmentación de fialücia en hispanorrománico», NRFH, 26 (1977 [-79]), 1-55. 